\title{
Risk factors associated with diabetic retinopathy among patients with type 2 diabetes mellitus in central India
}

\author{
Sonia Bano1, Vivek Som²*, Aditi Dubey ${ }^{3}$, Kavita Kumar ${ }^{4}$ \\ ${ }^{1}$ Resident Doctor, ${ }^{2}$ Associate Professor, ${ }^{3}$ Assistant Professor, ${ }^{4}$ Professor, Dept. of Ophthalmology, ${ }^{1}$ MPMSU, Jabalpur, Madhya Pradesh, \\ ${ }^{2-4}$ Gandhi Medical College Bhopal, Madhya Pradesh, India
}

\section{Article Info}

Received: $20^{\text {th }}$ June, 2019

Accepted: $19^{\text {th }}$ July, 2019

Published Online:

Keywords: Diabetes mellitus, Macular edema, Risk factors of diabetic retinopathy.

\begin{abstract}
Aim: To assess the clinical profile and association of various risk factors with severity of diabetic retinopathy (DR) in patients with type 2 diabetes mellitus (DM).

Materials and Methods: A prospective observational study included 56 patients (112 eyes) of type $2 \mathrm{DM}$ with DR. All cases underwent ophthalmic examination and severity of diabetic retinopathy was graded according to the modified ETDRS classification. Risk factors like age, gender, duration of DM, hypertension, HbA1C levels, haemoglobin level and serum lipid profile were studied for any association with severity of DR. Data were analyzed using standard statistical technique and a probability value ('p' value) of $<0.05$ was considered as statistically significant.

Results: The mean age of study group was $52.90 \pm 10.60$ years. M: F ratio was $2.3: 1.17 .86 \%$ were in Non -PDR, $28.60 \%$ in PDR and $53.60 \%$ were in advanced diabetic retinopathy. Severity of diabetic retinopathy was significantly associated with more duration of DM, high HbA1c level, Hypertension, anemia, dyslipidemia, positive family history of DM and low socioeconomic status.

Conclusion: Controlling modifiable risk factors like hypertension, dyslipidemia, high HbA1c level and anaemia are helpful in preventing the development and reducing the severity of diabetic retinopathy.
\end{abstract}

\section{Introduction}

Diabetes mellitus (DM) is gradually becoming major medical problem with increasing prevalence throughout the world. In 2008, almost 347 million people had diabetes mellitus in the world and the prevalence is increasing. India had 69.2 million people having diabetes $(8.7 \%)$ as per the 2015 data. [WHO]. There are almost 93 million people with diabetic retinopathy, 17 million with proliferative diabetic retinopathy, 21 million with diabetic macular edema, and 28 million with vision threatening DR in the world. ${ }^{1}$ Diabetic retinopathy is the cause of blindness in approxymately 2.5 million of the estimated 50 million blind people of the world. However, as a cause of blindness, it is less common in India as per population-based studies. ${ }^{2,3}$ India is set to emerge as the diabetic capital of the world. ${ }^{4}$ According to WHO, 31.7 million people were affected by DM in India in the year 2000. This figure is estimated to rise to 79.4 million by 2030 , the largest number in any nation in the world. Diabetic retinopathy is common in adult's age between 20 74 in developed country like United States of America and PDR is the main cause of vision loss. ${ }^{1,5}$

Diabetic retinopathy is a progressive micro vascular complication of diabetes, which is characterized by signs of retinal ischemia such as micro aneurysms; cotton wool spots
(CWS), hemorrhages, venous caliber abnormalities, intra retinal micro vascular abnormalities (IRMAs), neovascularization. ${ }^{6}$ If it is not controlled properly it leads to advanced diabetic retinopathy which is characterized by proliferative diabetic retinopathy, vitreous hemorrhage, tractional retinal detachment, rubeosis iridis and ultimately leads to irreversible blindness.

As per the avilable literature various risk factors including duration of diabetes, more age, gender, poor glycemic control, hypertension, deranged lipid profile, anemia, nephropathy, body mass index, smoking, socioeconomic status and family history of $\mathrm{DM}^{7,8}$ are significantly associated with development and progression of Diabetes retinopathy (DR).

The present study was conducted with the view of adding significantly to the current body of evidence by providing a collective report on associations of various potential risk factors with development and progression of diabetic retinopathy. The aim were to find severity status of DR in type 2 DM patients and to determine association between severity and more age, socioeconomic status, positive family history of DM, duration of DM, HbA1c level, hypertension, dyslipidemia and anemia.

\footnotetext{
*Corresponding Author: Vivek Som, Associate Professor, Dept. of Ophthalmology, Gandhi Medical College Bhopal, Madhya Pradesh, India

Email: drvsom@gmail.com

http://doi.org/10.18231/j.ijceo.2019.080
} 


\section{Materials and Methods}

This prospective observational study was carried out on 56 patients (112 eyes) with diabetic retinopathy for duration of one and half years (August 2016 to September 2018). Diabetes Mellitus patients with diabetic retinopathy attending ophthalmic OPD or vitero-retina clinic were included in this study and those with any other retinal pathology were excluded. Informed and written consent was obtained from each patient for participation in the study. The study was approved by institutional ethical committee and followed the declaration of helsinki. Data was spread in Microsoft excel sheet and descriptive statistics (mean and SD) were calculated for the variables. Test of significance (chi square and Anova test) wherever applicable, were applied, $(\mathrm{p}<0.05 \%)$ was taken significant at $95 \%$ confident interval.

The demographic details of patients were recorded. A brief history about presenting complaints, duration of diabetes, family history of DM, hypetension were taken. The ocular examination including Visual acuity on snellens chart, intraocular pressure by applanation tonometry were recorded. Slit-lamp examination of anterior segment to rule out iris neovascularization and cataract, Fundus examination by indirect ophthalmoscopy with volks $+20 \mathrm{D}$ lens, slit lamp biomicroscopy with $+90 \mathrm{D}$ lens were done. Fundus findings were recorded and fundus pictures were taken. Then patients were classified as per modified early treatment diabetic retinopathy study classification. Grading of disease was based on the worst eye findings. Patients having CSME were grouped separateraly from non CSME. Blood investigations like fasting blood sugar, post prandial blood sugar, glycosylated hemoglobin, renal function test, serum tryglicerides, High density lipoprotein (HDL), hemoglobin $(\mathrm{Hb})$ and low density lipoprotein (LDL) were done. Total cholesterol $>200 \mathrm{mg} / \mathrm{dl}$ or triglyceride $\geq 150 \mathrm{mg} / \mathrm{dl}$ or low density lipoprotein $>130 \mathrm{mg} / \mathrm{dl}$ were considered as dislipidemia.

\section{Results}

The present study included 56 patients (112 eyes) of type 2 DM with DR. Mean age in study participates was $52.90 \pm 10.60$ years. Maximum patients $44.6 \%$ were in the age group between 50-59 years. Out of total 56 cases, 39 $(69.6 \%)$ were males and $17(30.4 \%)$ were females with Male: Female ratio 2.3:1. With reference to grade of severity in study participants $17.9 \%$ were in non proliferative diabetic retinopathy (NPDR), $28.6 \%$ were proliferative diabetic retinopathy and $53.6 \%$ were in advanced diabetic eye disease.

The mean duration of diabetes was $12.30 \pm 8.8$ years. Duration of DM was found to be a significant risk factor for severity of DM ( $p$ value 0.017334 ) (Table 1).

Table 1: Association of various risk factors with severity of Diabetic Retinopathy

\begin{tabular}{|c|c|c|c|c|c|}
\hline & & NPDR & PDR & ADR & P value \\
\hline \multirow[t]{4}{*}{ Duration of DM (years) } & $\leq 5$ years & 4 & 1 & 1 & \multirow[t]{4}{*}{0.017334} \\
\hline & $6-10$ years & 3 & 3 & 4 & \\
\hline & $11-15$ years & 2 & 4 & 6 & \\
\hline & $\geq 16$ years & 1 & 8 & 19 & \\
\hline \multirow[t]{3}{*}{ HbA1c } & $<7 \%$ & 8 & 1 & 1 & \multirow{3}{*}{0.00001} \\
\hline & $7-9 \%$ & 1 & 2 & 1 & \\
\hline & $>9 \%$ & 1 & 13 & 28 & \\
\hline \multirow[t]{2}{*}{ Hypertension } & Present & 3 & 13 & 24 & \multirow[t]{2}{*}{0.0059579} \\
\hline & Absent & 7 & 3 & 6 & \\
\hline \multirow[t]{2}{*}{ Dyslipidemia } & Yes & 6 & 15 & 29 & \multirow[t]{2}{*}{0.004072} \\
\hline & No & 4 & 1 & 1 & \\
\hline \multirow[t]{2}{*}{ Hemoglobin } & $\leq 12 \mathrm{~g} / \mathrm{dl}$ & 3 & 13 & 27 & \multirow[t]{2}{*}{0.000453} \\
\hline & $>12 \mathrm{~g} / \mathrm{dl}$ & 7 & 3 & 3 & \\
\hline \multirow{2}{*}{$\begin{array}{l}\text { Family history of diabetes } \\
\text { mellitus }\end{array}$} & Yes & 2 & 9 & 25 & \multirow[t]{2}{*}{0.001042} \\
\hline & No & 8 & 7 & 5 & \\
\hline \multirow[t]{2}{*}{ Type of Diet } & Vegetarians & 6 & 7 & 10 & \multirow[t]{2}{*}{0.321421} \\
\hline & Non vegetarians & 4 & 9 & 20 & \\
\hline
\end{tabular}

Table 2: Association between CSME and Risk factors

\begin{tabular}{|l|c|c|c|c|}
\hline S. No & Factors Mean \pm SD & With CSME & Without CSME & P -value \\
\hline 1 & Duration of DM (Yrs) & $11.91 \pm 7.80$ & $12.84 \pm 10.24$ & 0.5870 \\
\hline 3 & HbA1c (\%) & $10.55 \pm 2.0$ & $9.03 \pm 2.83$ & $\mathbf{0 . 0 0 1 2}$ \\
\hline 4 & Hemoglobin (g \%) & $10.94 \pm 1.30$ & $11.10 \pm 1.60$ & 0.5621 \\
\hline 5 & Total Cholesterol (mg \%) & $226.13 \pm 39.0$ & $210.82 \pm 43.0$ & 0.0532 \\
\hline 6 & LDL (mg \%) & $142.75 \pm 6.33$ & $124.04 \pm 18.40$ & $\mathbf{0 . 0 0 0 1}$ \\
\hline 7 & HDL (mg \%) & $41.70 \pm 4.63$ & $43.81 \pm 7.44$ & 0.0669 \\
\hline
\end{tabular}


In present study the mean $\mathrm{HbA1C}$ was $10.0 \pm 2.52 \%$. The level of $\mathrm{HbA1C}$ was higher in patients with severe PDR than in patients with Non-PDR. High Glycosylated hemoglobin is significantly associated with more severe diabetic retinopathy with chi-square statistic 34.8044 and $\mathrm{p}$ value $0.00001(<0.05)$ (Table 1). Among Non proliferative diabetic retinopathy patients 3 were hypertensive and 7 were not. While among proliferative diabetic retinopathy 13 were hypertensive and 3 were not. Among advanced diabetic retinopathy patients 24 were hypertensive and 6 were not. On applying chi square test the statistic was 10.2462. The $\mathrm{p}$ value was $0.005957 \quad 9 \quad(<0.05) \quad($ Table 1$)$. Hence hypertension was found to be a significant risk factor for severe diabetic retinopathy. Deranged lipid profile was also significant risk factor for severe diabetic retinopathy with $\mathrm{p}$ value was 0.004072 (Table 1). Anemia also associated with severe diabetic retinopathy with $\mathrm{p}$ value 0.000453 (Table 1). Positive family history of DM is a significant risk factor for severity of diabetic retinopathy ( $\mathrm{p}$ value 0.001042 ) (Table 1). Patients of lower socioeconomic status had severe diabetic retinopathy ( $\mathrm{p}$ value $0.035919(<0.05)$. Age and diet were not risk factor for severity of DR in our study.

On comparing the CSME and non CSME group, the serum LDL level among the CSME group was $142.75 \pm 6.33 \mathrm{mg} \%$ which was significantly higher than the non CSME group $124.04 \pm 18.40 \mathrm{mg} \%$ (p value 0.0001 ) (Table 2). Glycosylated Haemoglobin (HbA1c) level among the CSME group $(10.55 \pm 2.0)$ was also significantly higher than the non CSME group (9.03 \pm 2.83$)$ with $\mathrm{p}$ value 0.0012 (Table 2).

\section{Discussion}

DM is a major cause of avoidable blindness. Diabetes is a multi-factorial disease. Knowledge of factors affecting the incidence and the severity of diabetic retinopathy are useful for preventing blindness as well as other micro-vascular complications of DM. Proper screening of diabetic patients and advising to control these factors will be useful for managing diabetic retinopathy.

In our study most of the patients (44.64\%) with diabetic retinopathy were in the age group between 50-59 years. The mean age of presentation in our study was $52.90 \pm 10.60$ years. Diagnosed diabetes is most prevalent in middle aged and elderly population. ${ }^{9}$ Similar types of results were shown by Senthilvel et al $(2017)^{10}$ in their study. The mean age in their study was $53.16 \pm 10.81$ years. Present study included predominantly male patients with Male: Female ratio 2.3:1. The probable reason was that males have easy access to health facility and awareness regarding complications of diabetes as compare to females. Similar observations were made by Senthilvel et al $(2017)^{10}$ in their study. Present study had majority of patients $(82.14 \%)$ with proliferative diabetic retinopathy (PDR). The probable reason was that patients included in our study were predominantly from rural area and low socioeconomic status so they had limited access of advanced health facilities, and lack of awareness regarding the complications of DM and irreversible visual loss due to it. Similar results were obtained by Senthilvel et al $(2017)^{10}$ in their study.

Age was not a significant risk factor for the severity of diabetic retinopathy in our study. Similar results were shown by Senthivel et al (2017) ${ }^{10}$ in their study. However age was a significant risk factor for the severity of diabetic retinopathy in Sannapaneni Krishnaiah et al (2007) ${ }^{11}$ study.

Duration of DM was a significant risk factor in our study. CURES (Chennai Urban Rural Epidemiology Eye Study) $(2008)^{12}$ and Irini P Chatziralli et al $(2010)^{13}$ found similar results in their study. In our study we found that patients with poor glycemic control (HbAlc $\geq 7 \%$ ) had more severe diabetic retinopathy than patients with good glycemic control (HbA1c <7\%). This coincides with the findings of CURES Eye Study (2008), ${ }^{12}$ DCCT (The Diabetes Control and Complications Trial) (1993), ${ }^{14}$ UKPDS (United Kingdom Prospective Diabetes Study) (1998), ${ }^{15}$ and Ramachandran Rajalakshmi et al (2016). ${ }^{16}$

On comparing patients with hypertension or without hypertension, we found that there was a statistically significant difference between the severities of diabetic retinopathy. Patients with hypertension had severe DR than patients without hypertension. Similar type of result was shown by Senthilvel Vasudevan et al (2017), ${ }^{10}$ Ramachandran Rajalakshmi et al (2016), ${ }^{16}$ UKPDS (1998) ${ }^{17}$ and Gallego et al $(2008)^{18}$ in their studies.

The severity of diabetic retinopathy between patients with normal lipid profile and patients with deranged lipid profile was compared in our study and found a statistically significant difference between these two. Diabetic retinopathy was severe in the later. This coincides with the findings of Ramachandran Rajalakshmi et al (2016), ${ }^{16}$ The Wisconsin Epidemiologic Study of DR XIII study (1991), ${ }^{19}$ ETDRS (1996) ${ }^{20}$ and CURES eye study $(2006)^{21}$ studies.

We also found a positive statistically significant association between low density lipoprotein level and clinically significant macular edema as high level of low density lipoprotein is associated with more number of hard exudates. Das et al (2015) ${ }^{22}$ study revealed same results in their study. The total cholesterol of patients with CSME was higher than patients without CSME in our study but the difference was not quite statistically significant. However there was a statistically significant association of raised total cholesterol with CSME in Das et al (2015) ${ }^{22}$ study.

Waqas Sami et al $(2017)^{23}$ concluded in their study that DM disease is almost confined to rich people who consumed oil, flour and sugar and they found diet rich in oil and sugar is significantly associated with severity of DM. However in present study baseline population belongs to rural area and low socioeconomic status so type of diet (vegetarian or non vegetarian) did not have any significant influence on severity of diabetic retinopathy.

Study conducted by Rand et al (1985), ${ }^{24}$ DCCT research group (1997), ${ }^{25} \mathrm{Ko} \mathrm{BC}$ et al $(1995)^{26}$ found that positive family history for DM was associated with more incidence and the severity of diabetic retinopathy. In our study as we included patients with diabetic retinopathy, there was a statistically significant association between 
positive family history and severity of DM. Senthilvel Vasudevan et al $(2017)^{10}$ also found the similar results.

In our study low socioeconomic status was associated with more severe diabetic retinopathy and the difference was statistically significant. Because people were not aware of complications of DM, majority of them came after developing complications. And also their compliance as well as affordability for treatment was not good. This coincides with the findings of Ronald Klein et al (1994) $)^{27}$ and Mitsuhiko Funakoshi et al (2017). ${ }^{28}$

\section{Conclusion}

Diabetes is a multi-factorial disease. Duration of DM, HbA1C levels, hypertension, anaemia, dyslipidemia, family history of DM, low socioeconomic status, were significant risk factors in our study. Age and diet was not a significant risk factor in this study. Knowledge of factors affecting the incidence and severity of diabetic retinopathy are to be useful for preventing blindness as well as other microvascular complications of DM.

\section{Source of Funding: None.}

\section{Conflict of Interest: None.}

\section{References}

1. Salil S Gadkari, Quresh B Maskati, Barun Kumar Nayak. Prevalence of diabetic retinopathy in India: The All India Ophthalmological Society Diabetic Retinopathy Eye Screening Study 2014. Indian J Ophthalmol. 2016;64(1):38-44.

2. Klein R, Klein BE K, Moss SE .The Wisconsin Epidemiologic Study of Diabetic Retinopathy. II. Prevalence and risk of diabetic retinopathy when age at diagnosis is less than 30 years. Arch Ophthalmol. 1984;102:520-6.

3. Klein R, Klein BEK, Moss SE. The Wisconsin Epidemiologic Study of Diabetic Retinopathy .III .Prevalence and risk of diabetic retinopathy when age at diagnosis is 30 or more years. Arch Ophthalmol. 1984;102:527-32.

4. Wild S, Roglic G, Green A .Global prevalence of diabetes, estimates for the year 2000 and projections for 2030. Diabetes Care. 2004;27:1047-53.

5. Sharma RA .Diabetic eye disease in southern India. Community Eye Health 1996;9:56-8.

6. Rema M, P Rema M, Ponnaiya M, Mohan V. Prevalence of retinopathy in non-insulin dependent diabetes mellitus at a diabetes centre in Southern India. Diabetes Res Clin Pract. 1996;34:29.

7. Dandona L, Dandona R, Naduvilath TJ. Population based assessment of diabetic retinopathy in an urban population in southern India. Br J Ophthalmol. 1999;83:937-40.

8. Rema M, Premkumar S, and Anitha B .Prevalence of diabetic retinopathy in urban India :The Chennai Urban Rural Epidemiology Study) CURES (eye study. Invest Ophthalmol Vis Sci. 2005;46:2328-33.

9. Waqas Sami, Tahir Ansari, Nadeem Shafique Butt, and Mohd Rashid Ab Hamid. Effect of diet on type 2 diabetes mellitus: A review. Int J Health Sci (Qassim). 2017;11(2):65-71.

10. Beulens JW, Patel A, Vingerling JR, Cruickshank JK, Hughes $\mathrm{AD}$, Stanton A, et al. Effects of blood pressure lowering and intensive glucose control on the incidence and progression of retinopathy in patients with type 2 diabetes mellitus: A randomised controlled trial. Diabetologia 2009;52:2027-36.
11. Goldberg MF, Jampol LM. Knowledge of diabetic retinopathy before and 18 years after the Airlie House Symposium on treatment of Diabetic Retinopathy. Ophthalmol. 1987;94:7416.

12. Mendanha DBA, Abrahão MM, Vilar MMC, Junior JJN. Risk factors and incidence of diabetic retinopathy. Rev Bras Oftalmol 2016;75(6).

13. G .K Dowse, A .R .G Humphrey, V .R Collins, W Plehwe, H Gareeboo, D Fareed. Prevalence and Risk Factors for Diabetic Retinopathy in the Multiethnic Population of Mauritius. Am J Epidemiol. 1998;147(5).

14. Chantelau E. Evidence that up regulation of serum IGF-1 concentration can trigger acceleration of diabetic retinopathy. Br J Ophthalmol. 1998; 82:725-30.

15. Rajalakshmi R, Prathiba V, Mohan V. Does tight control of systemic factors help in the management of diabetic retinopathy. Indian J Ophthalmol. 2016;6)1:62-8.

16. Tight blood pressure control and risk of macro vascular and micro vascular complications in type 2 diabetes :UKPDS 38 . UK Prospective Diabetes Study Group. BMJ 1998;317:703-13.

17. Fong DS, Segal PP, Myers F. Sub retinal fibrosis in diabetic macular edema. ETDRS report no 23. Arch Ophthalmol. 1997;115:873-7.

18. Lyons TJ, Jenkins AJ, Zhen D. Diabetic retinopathy and serum lipoprotein subclasses in the DCCT/EDIC cohort. Invest Ophthal Vis Sci. 2004;45:910-8.

19. Das R, Kerr R, Chakravarthy U, Hogg RE .Dyslipidemia and diabetic macular oedema: A systematic review and metaanalysis .Ophthalmol. 2015;122:1820-7.

20. Suehiro M, Ohkubo K, Kato H, Kido Y, Anzai K, Oshima K, et al. Analyses of serum lipoprotein)a (and the relation to phenotypes and genotypes of apolipoprotein)a (in type 2 diabetic patients with retinopathy. Exp Clin Endocrinol Diabetes. 2002;110:319-24.

21. Davis MD, Fisher MR, Gangnon RE. Risk factors for high-risk proliferative diabetic retinopathy and severe visual loss. ETDRS report no .18, Invest Ophthalmol Vis Sci. 1998;39:233-52.

22. Manaviat MR, Afkhami M, Shoja MR. Retinopathy and microalbuminuria in type II diabetic patients. $B M C$ Ophthalmol. 2004;4:9.

23. Diabetic Retinopathy Study Research Group. Report 7. A modification of the Airlie House classification of diabetic retinopathy. Invest Ophthalmol Vis Sci. 1981;21:210-26.

24. DCCT Research Group .Clustering of long-term complications in families with diabetes in the diabetes control and complications trial. Diabetes. 1997;46:1829-39.

25. R Serban, M Cioboata, C Chiotan, C Cornacel, R Liora, A Anghelie. Visual acuity outcome in patients with diabetic maculopathy. Med Life. 2014;7(2).

26. Ko BC, Lam KS, Wat NM. An A-C (n dinucleotide repeat polymorphic marker at the 5 'end of the aldose reductase gene is associated with early-onset diabetic retinopathy in NIDDM patients. Diabetes 1995;44:727-32.

27. Classification of diabetic retinopathy from fluorescence angiogram. ETDRS Report number 11. Early Treatment Diabetic Retinopathy Study Research Group. Ophthalmol 1991;98:807-22.

28. Wilkinson C. P., F. L. Ferris, $3^{\text {rd }}$, R. E. Klein, P. P. Lee, C. D. Agardh, M. Davis, et al. Proposed international clinical diabetic retinopathy and diabetic macular edema disease severity scales. Ophthalmol 2003;110:1677-82.

How to cite this article: Bano S, Som V, Dubey A, Kumar $\mathrm{K}$. Risk factors associated with diabetic retinopathy among patients with type 2 diabetes mellitus in central India. Indian J Clin Exp Ophthalmol 2019;5(3):335-8. 